\title{
Comparison of dietary intake patterns in hemodialysis patients by nutritional status: A cross-sectional analysis
}

\author{
Ji Eun Lee ${ }^{1(\mathbb{D})}$, Hyun-Jung Kim²(i) Mi Jung Lee ${ }^{3(\mathbb{D})}$, Young Eun Kwon ${ }^{4(\mathbb{D})}$, Min-Sook Kyung ${ }^{5(\mathbb{D})}$ Jung-Tak Park $^{6(\mathbb{D})}$,

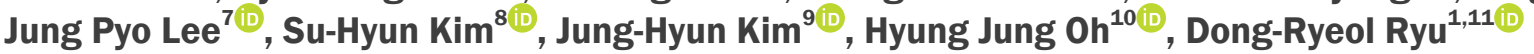 \\ 'Department of Internal Medicine, School of Medicine, Ewha Womans University, Seoul, Republic of Korea \\ ${ }^{2}$ College of Nursing, Ewha Womans University, Seoul, Republic of Korea \\ ${ }^{3}$ Department of Internal Medicine, CHA Bundang Medical Center, CHA University, Seongnam, Republic of Korea \\ ${ }^{4}$ Department of Internal Medicine, Myongji Hospital, Hanyang University College of Medicine, Goyang, Republic of Korea \\ ${ }^{5}$ Graduate School of Yonsei University, Major of Food and Nutrition, Seoul, Republic of Korea \\ ${ }^{6}$ Department of Internal Medicine, College of Medicine, Institute of Kidney Disease Research, Yonsei University, Seoul, Republic of Korea \\ ${ }^{7}$ Department of Internal Medicine, SMG-SNU Boramae Medical Center, Seoul, Republic of Korea \\ ${ }^{8}$ Division of Nephrology, Department of Internal Medicine, Chung-Ang University Hospital, Seoul, Republic of Korea \\ ${ }^{9}$ Department of Home Economics Education (Major of Food and Nutrition), Pai Chai University, Daejeon, Republic of Korea \\ ${ }^{10}$ Ewha Institute of Convergence Medicine, Ewha Womans University Mokdong Hospital, Seoul, Republic of Korea \\ ${ }^{1 " T i s s u e ~ I n j u r y ~ D e f e n s e ~ R e s e a r c h ~ C e n t e r, ~ C o l l e g e ~ o f ~ M e d i c i n e, ~ E w h a ~ W o m a n s ~ U n i v e r s i t y, ~ S e o u l, ~ R e p u b l i c ~ o f ~ K o r e a ~}$
}

Background: Although appropriate dietary adjustments in hemodialysis (HD) patients are important, most HD patients have difficulty adhering to dietary therapy due to the stress of a restricted-food diet or loss of appetite, which eventually leads to malnutrition and other complications. The dietary intake of HD patients stratified by nutritional status has not yet been studied.

Methods: In total, 111 HD patients from five dialysis centers were stratified into 2 groups based on the Subjective Global Assessment: the well-nourished group and the poorly nourished group. The 7-day dietary intake and food behaviors of the two groups were compared. Logistic regression analysis was performed to reveal the factors associated with poorly nourished status.

Results: The 7-day dietary survey showed a lower intake of total calories and protein and a higher intake of sodium and potassium than in the standard recommendations, but there were no differences between groups. The poorly nourished group ate fried food significantly more frequently than the well-nourished group. Moreover, higher hip and waist circumferences were significantly associated with poorly nourished status.

Received March 17, 2020; Revised April 27, 2020; Accepted April 27, 2020

Edited by Byung Ha Chung, The Catholic University of Korea, Seoul, Republic of Korea

Correspondence:

Hyung Jung Oh

Ewha Institute of Convergence Medicine and Research Institute for Human Health Information, Ewha Womans University, 1071 Anyangcheon-ro, Yangcheon-gu, Seoul 07985, Republic of Korea. E-mail: ohjmd@naver.com

Dong-Ryeol Ryu

Department of Internal Medicine, School of Medicine, Ewha Womans University, 1071 Anyangcheon-ro, Yangcheon-gu, Seoul o7985, Republic of Korea. E-mail: drryu@ewha.ac.kr

Copyright (C) 2020 by The Korean Society of Nephrology

(a) This is an open-access article distributed under the terms of the Creative Commons Attribution Non-Commercial License (http://creativecommons.org/ licenses/by-nc-nd/4.0/), which permits unrestricted non-commercial use, distribution, and reproduction in any medium, provided the original work is properly cited. 
Conclusion: We found differences in the dietary intake patterns and food behaviors between well- and poorly nourished HD patients. Further research is needed to design customized nutritional education, consultations, and dietary management for HD patients.

Keywords: Diet record, Malnutrition, Nutrition, Renal dialysis, Subjective global assessment

\section{Introduction}

The prevalence and incidence of end-stage renal disease (ESRD) have increased continuously around the world [1], and the prevalence of hemodialysis (HD) in Korea increased by $22.7 \%$ from 2009 to 2013 [2]. The annual mortality rate of chronic HD patients is much higher than that of the general population, and malnutrition is a major contributor to the increased morbidity and younger mortality seen in HD patients [3].

Most HD patients have difficulty adhering to dietary therapy due to the stress of a restricted-food diet or loss of appetite, which eventually leads to malnutrition and other complications [4]. Malnutrition is an abnormal status originating from an inadequate diet and is well known to aggravate various clinical outcomes [5]. The most commonly observed form of malnutrition is protein and energy depletion, also known as protein-energy wasting (PEW), and it is one of the strongest predictors of short-term mortality among dialysis patients [6]. Thus, in HD patients, regular assessment of nutritional status (including daily dietary intake) is necessary [7]. However, to the best of our knowledge, no previous study has compared the daily dietary intake of poorly nourished and well-nourished HD patients.

Several assessment tools are available to evaluate PEW or nutritional status in HD patients: the Subjective Global Assessment (SGA), Dialysis Malnutrition Score, Malnutrition Inflammation Score, etc. [8]. Among them, the SGA is a relatively inexpensive, easy, and rapidly conducted tool used by nurses, dietitians, and physicians to assess PEW in chronic HD patients [9]. It is also used to examine the nutritional status of HD patients [10], and several studies have evaluated the relationship between SGA scores and mortality in HD patients [11]. Therefore, we divided HD patients into two groups (well-nourished vs. poorly nourished) based on the SGA and compared their dietary intake levels and food intake patterns.

\section{Methods}

\section{Target population and study duration}

One hundred twenty-seven HD patients from five dialysis centers in Seoul, South Korea, were screened for participation. Three patients were excluded due to transfer to other hospitals or rejection from the study, and 16 patients' files were unavailable due to low compliance and non-response. Therefore, $111 \mathrm{HD}$ patients were enrolled in this study. All participants were told the purpose of the study, agreed with it, and participated in the study voluntarily. Questionnaires were administered in one-on-one interviews from January 13 to March 22, 2017.

\section{Contents of the research and methods}

\section{Baseline characteristics}

A questionnaire and review of medical charts was performed by patients and trained investigators together to obtain accurate general information, including sex, age, level of family support, smoking status, comorbidities, medications used, and other dialysis information. Information about disease severity was calculated by the Charlson comorbidity index (CCI) score, which is commonly used to assess short-term mortality risk in HD patients [12]. The CCI score was calculated during review of each patient's medical chart using International Classification of Diseases, 9th Revision (ICD-9) disease codes and scores for 19 diagnoses (Supplementary Table 1, available online). The score was categorized as $\leq 4$ points and $>5$ points, with a higher score indicating a lower probable 10-year survival rate. In addition, a physical examination collected information about blood pressure, neck circumference, waist circumference, upper arm circumference, triceps skinfold thickness, grip strength, and body mass index (BMI). Body weight was measured immediately after HD, and then BMI was calculated. According to the Asia-Pacific BMI classification, BMI 
was categorized as underweight $\left(<18.5 \mathrm{~kg} / \mathrm{m}^{2}\right)$, normal weight ( 18.5 to $\left.<22.9 \mathrm{~kg} / \mathrm{m}^{2}\right)$, and overweight ( $\geq 23 \mathrm{~kg}$ / $\mathrm{m}^{2}$ ). The study was approved by the ethical committee at each participating center (Supplementary materials).

\section{Biochemical laboratory analysis}

Blood samples were collected once a month prior to $\mathrm{HD}$, and the white blood cell count was measured, along with the levels of white blood cell, hemoglobin, aspartate aminotransferase, alanine aminotransferase, total bilirubin, alkaline phosphatase, calcium, phosphorus, uric acid, HbAlc, serum total protein, albumin, high sensitivity C-reactive protein, single-pool Kt/V, blood urea nitrogen (BUN), creatinine, sodium, potassium, chloride, bicarbonate, parathyroid hormone, ferritin, iron, total iron binding capacity (TIBC), total cholesterol, low density lipoprotein cholesterol and triglycerides.

\section{Subjective Global Assessment}

The nutritional status of each HD patient was evaluated using the 7-point SGA. The SGA was originally developed to evaluate the nutritional status of patients with post-operative infection or cancer, but its feasibility in assessing the nutritional status of HD patients has been verified [13]. Therefore, the SGA is recommended by the National Kidney Foundation and the Kidney Disease/Dialysis Outcomes and Quality Initiative (KDOQI) as an assessment tool for examining the nutritional status of HD patients [14]. The questionnaire-based SGA assesses the following: weight changes in the past 6 months, changes in dietary intake (duration and range of food intake), gastrointestinal symptoms persisting for 2 weeks, functional status, disease states affecting nutritional requirements, and physical changes such as edema, ascites, sacral edema, ankle edema, muscle atrophy, and loss of subcutaneous fat [15]. The questionnaires were translated into Korean and filled out by patients and trained investigators together. Each item was rated from 1 to 7 points: 1) 1-2 points for weight loss of more than $10 \%, 3-5$ points for weight loss of $5 \%-10 \%$, and $6-7$ points for weight loss of less than $5 \%$ in the past 6 months; 2 ) according to the degree of changes in dietary intake, gastrointestinal symptoms persisting for 2 weeks, functional status, disease states, and physical examination, 1-2 points were given for moderate to severe, $3-5$ points for mild to moderate, and 6-7 points for normal to mild. All these data were summed to calculate the overall SGA rating. In addition, based on the overall SGA score trend, 1-7 points were assigned again to give the subjective SGA rating. Patients were classified into three categories based on those final ratings: 1-2 points for the severely malnourished group, 3-5 points for the moderately malnourished group, and 6-7 points for the well-nourished group [16]. Because only two patients fit into the severely malnourished group, we categorized the patients into two groups: $1-5$ points for the poorly nourished group and $6-7$ points for the well-nourished group (Supplementary Table 2).

\section{Study design}

The study design is presented in Fig. 1. We investigated food intake prior to each dialysis center visit for 7 days using 24-hour dietary recall documentation (example in Supplementary Table 3), which we call our '7-day dietary intake research.' We also investigated food behavior on two occasions (the 1st and 8th days of the study) to reduce individual variation after calculating the 2-day intake (Supplementary Table 4).

\section{Seven-day dietary intake research}

For the 7-day dietary intake research, dieticians assessed all food items and amounts patients consumed during 7 days of visits to the dialysis center. Using 24-hour dietary recall documentation, the patients recalled and recorded all the food items and amounts they consumed from discharge from their previous dialysis center visit to immediately before the present visit. The dietitians were well-educated and trained. Paper cups, measuring cups, and measuring spoons were provided to the patients to help them measure their food intake more accurately. In the case of processed foods, patients were required to

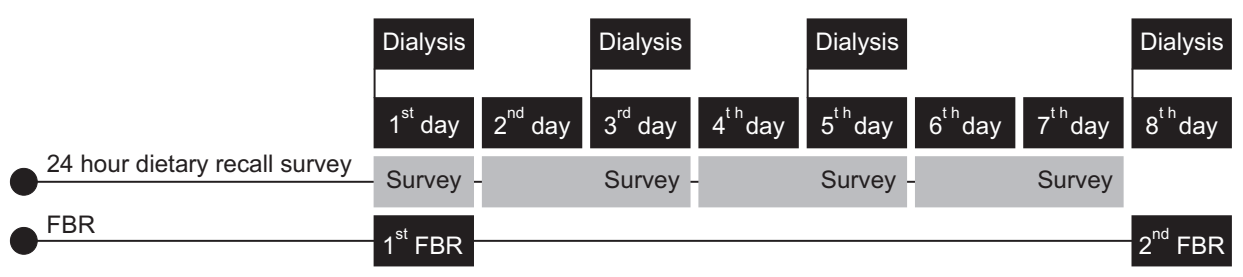
FBR
Figure 1. Study design: actual food intake survey for the 7-day dietary intake research and food behavior research (FBR). 
fill out the label of the food and provide the name of the company (Supplementary Table 3).

\section{Food behavior research}

As shown in Supplementary Table 4, patients were asked several questions about their food behaviors, such as how many times they ate per day and how frequently they ate out. We used that information to determine the patients' eating patterns and characteristics.

\section{Calculation of food intake}

Patients' intake of calories, carbohydrates, protein, lipids, etc. were calculated in CAN-Pro 4.0 (Computer Aided Nutritional Analysis Program) (The Korean Nutrition Society; 2011) (Internet: http://www.kns.or.kr/Center/ CanPro5.asp), a nutrition-evaluating program, based on the data collected from the 7-day dietary intake research.

\section{Statistical analysis}

All results were analyzed in IBM SPSS Windows ver. 21.0 (IBM Corp., Armonk, NY, USA). Subjects' baseline characteristics were compared and computed with the ratio of frequent numbers. Based on the SGA, differences in baseline characteristics and nutrient intake were compared by the student's $t$ test or $\chi^{2}$ test. Univariate logistic regression analyses were performed with the independent variables (waist circumference, hip circumference, BMI, mean inter-dialytic weight gain, hemoglobin level, albumin level, energy intake, carbohydrate intake, protein intake, fluid intake, mineral intake, food intake, and fried food intake). In addition, variables with a significant $P$ value were used in a multivariate logistic regression analysis adjusted by age, sex, CCI score, comorbidities, smoking status, alcohol intake status, and medication use to determine the factors associated with nutritional status. Odds ratios (ORs) and $95 \%$ confidence intervals (CIs) were used to determine the relative associations between several factors and nutritional status. A $P$ value of less than 0.05 was considered statistically significant.

\section{Results}

Baseline characteristics at enrollment in the wellnourished and poorly nourished groups

Among the 111 patients enrolled, 24 (21.6\%) were younger than 50 years, and 65 were male (58.6\%). Most of the patients had been undergoing HD for more than 10 months $(91.9 \%)$, and 44 patients $(39.6 \%)$ had a CCI score above 5 . In addition, most of the patients took medications such as erythropoiesis-stimulating agents (76.6\%), iron supplements (69.4\%), antihypertensive agents (87.4\%), and antiplatelet agents (55.9\%), and 58 patients (52.3\%) had diabetes mellitus. Moreover, 53 patients $(47.7 \%)$ required family support to eat or move $(45.9 \%$ requiring $50 \%-99 \%$ family support, and $1.8 \%$ requiring $100 \%$ family support). Most of the patients were nonsmokers (77.5\%), and nearly half were overweight (BMI $\geq$ $\left.23.0 \mathrm{~kg} / \mathrm{m}^{2}, 47.7 \%\right)$. The mean SGA rating was $5.99 \pm 2.00$ points; the mean waist-to-hip-circumference ratio was $0.92 \mathrm{~cm} / \mathrm{cm}$; and the mean calcium, phosphorus, and albumin levels were $8.79 \mathrm{mg} / \mathrm{dL}, 5.26 \mathrm{mg} / \mathrm{dL}$, and $3.88 \mathrm{~g} /$ $\mathrm{dL}$, respectively. In addition, the mean height was $162.28 \pm$ $9.81 \mathrm{~cm}$, and the mean weight before HD, mean weight after $\mathrm{HD}$, and mean inter-dialytic weight gain were $62.92 \pm$ $15.46 \mathrm{~kg}, 60.78 \pm 15.30 \mathrm{~kg}$, and $2.13 \pm 0.99 \mathrm{~kg}$, respectively.

When the enrolled HD patients were divided into two groups (well-nourished group and poorly nourished group) based on their SGA scores, $30(27.0 \%)$ were in the poorly nourished group. The SGA rating was significantly higher in the well-nourished group than in the poorly nourished group $(6.61 \pm 1.00$ points in the well-nourished group vs. $4.30 \pm 1.00$ points in the poorly nourished group, $P=0.001$ ). As shown in Table 1 , the proportions of patients younger than 50 years and male did not differ significantly between the two groups. Moreover, the mean inter-dialytic weight gain was higher in the poorly nourished group $(2.56 \pm 0.75 \mathrm{~kg})$ than in the well-nourished group $(1.98 \pm 1.03 \mathrm{~kg})$, but that difference was not significant. Dialysis vintage, comorbidities, weight, height, family support, and CCI score did not differ significantly between the two groups, but BMI was significantly higher in the well-nourished group than in the poorly nourished group $\left(23.81 \pm 3.91 \mathrm{~kg} / \mathrm{m}^{2}\right.$ in the well-nourished group vs. $22.03 \pm 2.54 \mathrm{~kg} / \mathrm{m}^{2}$ in the poorly nourished group, $P=0.007$; overweight, $56.8 \%$ in the well-nourished group vs. $23.3 \%$ 
Table 1. Baseline characteristics in the two groups stratified by nutritional status

\begin{tabular}{|c|c|c|c|c|}
\hline \multirow[b]{2}{*}{ Characteristic } & \multirow[b]{2}{*}{$\begin{array}{c}\text { Total } \\
(n=111)\end{array}$} & \multicolumn{2}{|c|}{ Nutritional status } & \multirow[b]{2}{*}{$P$ value } \\
\hline & & $\begin{array}{l}\text { Well-nourished group } \\
\quad(n=81,73 \%)\end{array}$ & $\begin{array}{l}\text { Poorly nourished group } \\
\qquad(\mathrm{n}=30,27 \%)\end{array}$ & \\
\hline Male & $65(58.6)$ & $50(61.7)$ & $15(50.0)$ & 0.265 \\
\hline SGA rating (point) & $5.99 \pm 2.00$ & $6.61 \pm 1.00$ & $4.30 \pm 1.00$ & 0.001 \\
\hline \multicolumn{5}{|l|}{ Dialysis period } \\
\hline $10 \mathrm{mo} \leq x<50 \mathrm{mo}$ & 37 (33.3) & $26(32.1)$ & $11(36.7)$ & \multirow{3}{*}{0.279} \\
\hline $50 \mathrm{mo} \leq x<100 \mathrm{mo}$ & $43(38.7)$ & 35 (43.2) & $8(26.7)$ & \\
\hline$\geq 100 \mathrm{mo}$ & $22(19.8)$ & $15(18.5)$ & $7(23.3)$ & \\
\hline \multicolumn{5}{|l|}{ CCl score (point) } \\
\hline$\leq 4$ & $28(25.2)$ & $23(28.4)$ & $5(16.7)$ & 0.062 \\
\hline ESAs & $85(76.6)$ & $62(76.5)$ & $23(76.7)$ & 0.989 \\
\hline Iron supplements & $77(69.4)$ & $52(64.2)$ & $25(83.3)$ & 0.052 \\
\hline Antihypertensive agents & $97(87.4)$ & $69(85.2)$ & 28 (93.3) & 0.251 \\
\hline Antiplatelet agents & $62(55.9)$ & $46(56.8)$ & $16(53.3)$ & 0.745 \\
\hline Diuretics & $35(31.5)$ & 25 (30.9) & $10(33.3)$ & 0.804 \\
\hline \multicolumn{5}{|l|}{ Comorbidities } \\
\hline Diabetes & $58(52.3)$ & $40(49.4)$ & $18(60.0)$ & 0.670 \\
\hline Myocardial infarction & $3(2.7)$ & $2(2.5)$ & $1(3.3)$ & 0.732 \\
\hline Heart failure & $6(5.4)$ & $3(3.7)$ & $3(10.0)$ & 0.154 \\
\hline \multicolumn{5}{|l|}{ Social history } \\
\hline \multicolumn{5}{|l|}{ Degree of family support } \\
\hline 0\% (Independent) & $22(19.8)$ & $18(22.2)$ & $4(13.3)$ & \multirow[t]{5}{*}{0.115} \\
\hline $0 \%<x<50 \%$ & $32(28.8)$ & $23(28.4)$ & $9(30.0)$ & \\
\hline $50 \% \leq x<100 \%$ & $51(45.9)$ & $38(46.9)$ & $13(43.3)$ & \\
\hline $100 \%$ (fully dependent) & $2(1.8)$ & $0(0.0)$ & $2(6.7)$ & \\
\hline Unknown & $4(3.6)$ & $2(2.5)$ & $2(6.7)$ & \\
\hline \multicolumn{5}{|l|}{ Physical examination } \\
\hline $\mathrm{SBP}(\mathrm{mmHg})$ & $142.73 \pm 21.86$ & $142.19 \pm 22.30$ & $144.20 \pm 20.92$ & 0.670 \\
\hline $\mathrm{DBP}(\mathrm{mmHg})$ & $75.07 \pm 13.72$ & $75.00 \pm 13.24$ & $75.26 \pm 15.18$ & 0.928 \\
\hline Neck circumference (cm) & $37.33 \pm 6.72$ & $36.94 \pm 5.39$ & $38.40 \pm 9.54$ & 0.327 \\
\hline Hip circumference (cm) & $83.41 \pm 24.81$ & $81.37 \pm 27.55$ & $89.30 \pm 12.89$ & 0.049 \\
\hline Waist circumference $(\mathrm{cm})$ & $77.74 \pm 23.92$ & $75.40 \pm 26.50$ & $84.26 \pm 12.77$ & 0.024 \\
\hline Waist to hip circumference ratio & $0.92 \pm 0.06$ & $0.92 \pm 0.06$ & $0.94 \pm 0.04$ & 0.209 \\
\hline Upper arm circumference $(\mathrm{cm})$ & $28.50 \pm 7.62$ & $28.78 \pm 8.57$ & $27.73 \pm 3.98$ & 0.537 \\
\hline Triceps skinfold thickness (cm) & $12.46 \pm 8.33$ & $11.73 \pm 8.33$ & $14.49 \pm 8.11$ & 0.133 \\
\hline Grip strength (kg) & $23.14 \pm 9.43$ & $23.88 \pm 9.96$ & $21.02 \pm 7.46$ & 0.124 \\
\hline
\end{tabular}




\begin{tabular}{|c|c|c|c|c|}
\hline \multirow[b]{2}{*}{ Characteristic } & \multirow[b]{2}{*}{$\begin{array}{c}\text { Total } \\
(n=111)\end{array}$} & \multicolumn{2}{|c|}{ Nutritional status } & \multirow[b]{2}{*}{$P$ value } \\
\hline & & $\begin{array}{l}\text { Well-nourished group } \\
\qquad(n=81,73 \%)\end{array}$ & $\begin{array}{l}\text { Poorly nourished group } \\
\qquad(\mathrm{n}=30,27 \%)\end{array}$ & \\
\hline Height (cm) & $162.28 \pm 9.81$ & $161.87 \pm 9.46$ & $163.41 \pm 10.80$ & 0.797 \\
\hline Weight pre-HD (kg) & $62.92 \pm 15.46$ & $62.58 \pm 16.79$ & $63.88 \pm 11.35$ & 0.474 \\
\hline Weight post-HD (kg) & $60.78 \pm 15.30$ & $60.59 \pm 16.57$ & $61.31 \pm 11.43$ & 0.885 \\
\hline Inter-dialytic weight gain (kg) & $2.13 \pm 0.99$ & $1.98 \pm 1.03$ & $2.56 \pm 0.75$ & 0.073 \\
\hline Body mass index $\left(\mathrm{kg} / \mathrm{m}^{2}\right)$ & $23.34 \pm 3.67$ & $23.81 \pm 3.91$ & $22.03 \pm 2.54$ & 0.007 \\
\hline \multicolumn{5}{|l|}{ Body mass index } \\
\hline Underweight $\left(<18.5 \mathrm{~kg} / \mathrm{m}^{2}\right)$ & $9(8.1)$ & $7(8.6)$ & $2(6.7)$ & 0.004 \\
\hline Normal weight $\left(18.5 \leq x<22.9 \mathrm{~kg} / \mathrm{m}^{2}\right)$ & $47(42.3)$ & 27 (33.3) & $20(66.7)$ & \\
\hline Overweight ( $\geq 23.0 \mathrm{~kg} / \mathrm{m}^{2}$ ) & $53(47.7)$ & $46(56.8)$ & 7 (23.3) & \\
\hline \multicolumn{5}{|l|}{ Laboratory findings } \\
\hline White blood cell $\left(/ \mathrm{mm}^{3}\right)$ & $6,209.46 . \pm 2,400.00$ & $6,040.00 \pm 2,475.00$ & $6,045.67 \pm 1,817.50$ & 0.558 \\
\hline Hemoglobin (g/dL) & $10.66 \pm 1.34$ & $10.81 \pm 1.39$ & $10.25 \pm 1.10$ & 0.030 \\
\hline AST (IU/L) & $20.01 \pm 9.21$ & $19.65 \pm 7.96$ & $21.00 \pm 12.08$ & 0.497 \\
\hline $\operatorname{ALT}(\mathrm{IU} / \mathrm{L})$ & $17.09 \pm 11.04$ & $16.29 \pm 8.80$ & $19.26 \pm 15.56$ & 0.210 \\
\hline Total bilirubin (mg/dL) & $0.54 \pm 0.89$ & $0.59 \pm 1.06$ & $0.43 \pm 0.23$ & 0.418 \\
\hline Alkaline phosphatase (IU/dL) & $155.90 \pm 78.00$ & $105.97 \pm 42.00$ & $289.03 \pm 166.50$ & 0.103 \\
\hline Calcium (mg/dL) & $8.79 \pm 0.67$ & $8.78 \pm 0.65$ & $8.81 \pm 0.74$ & 0.854 \\
\hline Phosphorus (mg/dL) & $5.26 \pm 1.52$ & $5.28 \pm 1.45$ & $5.22 \pm 1.74$ & 0.863 \\
\hline Uric acid (mg/dL) & $6.83 \pm 1.51$ & $6.85 \pm 1.65$ & $6.78 \pm 1.06$ & 0.830 \\
\hline HbA1c (\%) & $7.11 \pm 1.64$ & $6.91 \pm 1.50$ & $12.51 \pm 2.13$ & 0.283 \\
\hline Total protein $(\mathrm{g} / \mathrm{dL})$ & $6.60 \pm 0.73$ & $6.67 \pm 0.80$ & $6.41 \pm 0.46$ & 0.106 \\
\hline Albumin (g/dL) & $3.88 \pm 0.32$ & $3.92 \pm 0.33$ & $3.77 \pm 0.26$ & 0.032 \\
\hline Hs-CRP (mg/dL) & $2.53 \pm 7.09$ & $2.47 \pm 7.55$ & $2.74 \pm 5.47$ & 0.239 \\
\hline $\mathrm{spKt} / \mathrm{V}$ & $1.56 \pm 0.30$ & $1.55 \pm 0.29$ & $1.58 \pm 0.33$ & 0.680 \\
\hline BUN (mg/dL) & $59.61 \pm 17.76$ & $59.24 \pm 17.86$ & $60.61 \pm 17.76$ & 0.720 \\
\hline Creatinine (mg/dL) & $10.10 \pm 8.11$ & $10.32 \pm 9.43$ & $9.53 \pm 1.95$ & 0.650 \\
\hline Sodium (mmol/L) & $137.68 \pm 3.11$ & $137.45 \pm 3.18$ & $138.30 \pm 2.90$ & 0.207 \\
\hline Potassium (mmol/L) & $5.34 \pm 3.57$ & $5.50 \pm 4.15$ & $4.92 \pm 0.77$ & 0.453 \\
\hline Chloride (mmol/L) & $96.18 \pm 7.59$ & $95.87 \pm 8.82$ & $96.82 \pm 4.11$ & 0.593 \\
\hline Bicarbonate (mmol/L) & $22.25 \pm 3.10$ & $22.31 \pm 2.89$ & $22.08 \pm 3.65$ & 0.736 \\
\hline Intact PTH (pg/mL) & $262.81 \pm 231.75$ & $251.60 \pm 204.03$ & $292.70 \pm 268.63$ & 0.317 \\
\hline Ferritin $(\mathrm{ng} / \mathrm{mL})$ & $298.04 \pm 304.30$ & $319.29 \pm 325.04$ & $241.37 \pm 155.85$ & 0.105 \\
\hline $\operatorname{Iron}(\mu \mathrm{g} / \mathrm{dL})$ & $74.68 \pm 34.36$ & $76.06 \pm 30.67$ & $70.96 \pm 43.17$ & 0.490 \\
\hline $\mathrm{TIBC}(\mu \mathrm{g} / \mathrm{dL})$ & $231.73 \pm 42.61$ & $231.71 \pm 45.76$ & $231.80 \pm 33.33$ & 0.993 \\
\hline Total cholesterol (mg/dL) & $149.12 \pm 35.64$ & $146.12 \pm 34.67$ & $157.13 \pm 37.54$ & 0.150 \\
\hline LDL cholesterol (mg/dL) & $81.18 \pm 30.40$ & $81.93 \pm 29.84$ & $79.20 \pm 32.28$ & 0.682 \\
\hline Triglycerides (mg/dL) & $125.03 \pm 82.66$ & $120.73 \pm 81.96$ & $136.50 \pm 84.83$ & 0.376 \\
\hline
\end{tabular}

Data are expressed as number () or mean \pm standard deviation. $P$ values indicate comparisons between well-nourished and poorly nourished group.

ALT, alanine aminotransferase; AST, aspartate aminotransferase; BUN, blood urea nitrogen; CCl, Charlson comorbidity index; DBP, diastolic blood pressure; ESA, erythropoiesis-stimulating agent; HD, hemodialysis; hs-CRP, high sensitivity C-reactive protein; LDL, low density lipoprotein; PTH, parathyroid hormone; SBP, systolic blood pressure; SGA, Subjective Global Assessment; spKt/V, single-pool Kt/V; TIBC, total iron binding capacity.

in the poorly nourished group, $P=0.004$ ), and the hip and waist circumferences were significantly lower in the wellnourished group than in the poorly nourished group.
Laboratory testing revealed that hemoglobin and serum albumin levels were significantly higher in the wellnourished group than in the poorly nourished group 
(hemoglobin: $10.81 \mathrm{~g} / \mathrm{dL}$ in the well-nourished group vs. $10.25 \mathrm{~g} / \mathrm{dL}$ in the poorly nourished group, $P=0.030$; serum albumin: $3.92 \mathrm{~g} / \mathrm{dL}$ in the well-nourished group vs. $3.77 \mathrm{~g} / \mathrm{dL}$ in the poorly nourished group, $P=0.032$ ). Serum calcium, phosphorus, uric acid, BUN, creatinine, iron, TIBC, total cholesterol, and intact parathyroid hormone levels did not differ significantly between the two groups (Table 1).

\section{Nutrient intake status evaluated by 7-day dietary research}

We assessed what, how much, and how often patients ate through our 7-day dietary research. We also examined the composition of the foods eaten (carbohydrates, protein, lipids, etc.) and calculated patients' intake of calories, dietary fiber, and minerals. As shown in Table

Table 2. Results of the seven-day dietary research in two groups stratified by nutritional status

\begin{tabular}{|c|c|c|c|c|}
\hline & \multicolumn{3}{|c|}{ Nutritional status } & \multirow[b]{2}{*}{$P$ value } \\
\hline & $\begin{array}{c}\text { Total } \\
(n=111)\end{array}$ & $\begin{array}{l}\text { Well-nourished group } \\
\qquad(\mathrm{n}=81,73 \%)\end{array}$ & $\begin{array}{l}\text { Poorly nourished group } \\
\qquad(\mathrm{n}=30,27 \%)\end{array}$ & \\
\hline \multicolumn{5}{|c|}{ Major nutrient components } \\
\hline Carbohydrates (g/d) & $214.54 \pm 62.54$ & $217.09 \pm 63.24$ & $207.65 \pm 61.13$ & 0.483 \\
\hline Lipids (g/d) & $36.43 \pm 14.07$ & $36.75 \pm 14.42$ & $35.54 \pm 13.24$ & 0.688 \\
\hline \multicolumn{5}{|c|}{ Fluid and mineral components } \\
\hline Total fiber $(\mathrm{g} / \mathrm{d})$ & $14.55 \pm 5.90$ & $14.89 \pm 6.28$ & $13.65 \pm 4.70$ & 0.326 \\
\hline Water $(\mathrm{mL} / \mathrm{d})$ & $589.06 \pm 217.75$ & $602.08 \pm 219.28$ & $553.89 \pm 213.19$ & 0.303 \\
\hline Calcium (mg/d) & $349.33 \pm 140.35$ & $355.41 \pm 139.50$ & $332.91 \pm 143.70$ & 0.456 \\
\hline Phosphate (mg/d) & $760.61 \pm 250.64$ & $777.48 \pm 255.56$ & $715.07 \pm 234.88$ & 0.246 \\
\hline Iron (mg/d) & $11.48 \pm 4.16$ & $11.75 \pm 4.41$ & $10.74 \pm 3.33$ & 0.258 \\
\hline
\end{tabular}

Data are expressed as mean \pm standard deviation. $P$ values indicate comparisons between well-nourished and poorly nourished group.

Table 3. Comparison of food intake behavior by nutritional status

\begin{tabular}{|c|c|c|c|}
\hline \multirow[b]{2}{*}{ Dietary habits or behaviors ${ }^{a}$} & \multicolumn{2}{|c|}{ Nutritional status } & \multirow[b]{2}{*}{$P$ value } \\
\hline & $\begin{array}{l}\text { Well-nourished group } \\
\qquad(\mathrm{n}=81,73 \%)\end{array}$ & $\begin{array}{l}\text { Poorly nourished group } \\
\qquad(\mathrm{n}=30,27 \%)\end{array}$ & \\
\hline \multicolumn{4}{|l|}{ How many times in a week have you ... } \\
\hline Eaten three meals per day & $1.35 \pm 0.80$ & $1.23 \pm 0.75$ & 0.463 \\
\hline Eaten various nutrients & $1.21 \pm 0.66$ & $0.96 \pm 0.62$ & 0.078 \\
\hline How many fruits have you eaten per day & $1.02 \pm 0.79$ & $1.06 \pm 0.70$ & 0.800 \\
\hline How much milk have you drunk per day & $0.37 \pm 0.56$ & $0.41 \pm 0.64$ & 0.751 \\
\hline No. of behaviors to reduce potassium & $1.04 \pm 0.83$ & $1.15 \pm 0.81$ & 0.571 \\
\hline No. of salted or processed foods eaten & $1.80 \pm 0.45$ & $1.61 \pm 0.58$ & 0.111 \\
\hline Eaten more than two protein-rich meals per day & $1.19 \pm 0.74$ & $0.93 \pm 0.75$ & 0.110 \\
\hline Eaten sweet foods & $0.85 \pm 0.69$ & $0.80 \pm 0.63$ & 0.721 \\
\hline Eaten fried foods & $0.51 \pm 0.71$ & $0.85 \pm 0.70$ & 0.029 \\
\hline Remembered how much water to drink per day & $1.34 \pm 0.73$ & $1.33 \pm 0.64$ & 0.968 \\
\hline Eaten out & $0.66 \pm 0.75$ & $1.05 \pm 0.83$ & 0.023 \\
\hline
\end{tabular}

Data are expressed as mean \pm standard deviation.

a Several questions in Supplementary Table 2 were asked only two times, at the initiation of the study and the end of the study. We present the average of those two points in this table. 
2, the mean total caloric intake was $23.44 \mathrm{kcal} / \mathrm{kg} / \mathrm{d}$, and the mean carbohydrate, lipid, and protein intake was $214.54 \mathrm{~g} / \mathrm{d}, 36.43 \mathrm{~g} / \mathrm{d}$, and $0.92 \mathrm{~g} / \mathrm{kg} / \mathrm{d}$, respectively. Patients consumed an average of $349.33 \mathrm{mg} / \mathrm{d}$ of calcium, $760.61 \mathrm{mg} / \mathrm{d}$ of phosphorus, $3,285.86 \mathrm{mg} / \mathrm{d}$ of sodium, and $1,856.91 \mathrm{mg} / \mathrm{d}$ of potassium. No significant differences emerged between the well-nourished and poorly nourished groups in the factors measured in the 7-day dietary research (Table 2).

\section{Food behavior research}

Table 3 presents the results of the food behavior research. The frequency of eating out was significantly higher in the poorly nourished group than in the wellnourished group. Moreover, the poorly nourished group ate fried food significantly more frequently than the wellnourished group. The number of patients eating three meals/d and eating various nutrients and the amount of fruit eaten per day did not differ significantly between the

Table 4. Logistic regression analysis for the factors associated with poorly nourished status

\begin{tabular}{|c|c|c|c|}
\hline Factors & Odds ratio & 95\% confidence interval & $P$ value \\
\hline Hip circumference, per increase of $1 \mathrm{~cm}$ & 1.032 & $1.002-1.063$ & 0.036 \\
\hline Waist circumference, per increase of $1 \mathrm{~cm}$ & 1.035 & $1.004-1.066$ & 0.027 \\
\hline Body mass index, per increase of $1 \mathrm{~kg} / \mathrm{m}^{2}$ & 0.857 & $0.746-0.984$ & 0.028 \\
\hline Mean inter-dialytic weight gain, per increase of $1 \mathrm{~kg}$ & 1.335 & $0.914-1.949$ & 0.135 \\
\hline Hemoglobin, per increase of $1 \mathrm{~g} / \mathrm{dL}$ & 0.696 & $0.483-1.003$ & 0.052 \\
\hline Albumin, per increase of $1 \mathrm{~g} / \mathrm{dL}$ & 0.237 & $0.059-0.944$ & 0.041 \\
\hline Energy, per increase of $1 \mathrm{kcal} / \mathrm{kg} / \mathrm{d}$ & 1.000 & $0.998-1.001$ & 0.429 \\
\hline Carbohydrates, per increase of $1 \mathrm{~g} / \mathrm{d}$ & 0.997 & $0.990-1.005$ & 0.480 \\
\hline Lipids, per increase of $1 \mathrm{~g} / \mathrm{d}$ & 0.994 & $0.964-1.024$ & 0.685 \\
\hline Protein, per increase of $1 \mathrm{~g} / \mathrm{kg} / \mathrm{d}$ & 0.990 & $0.969-1.012$ & 0.374 \\
\hline Water, per increase of $1 \mathrm{~mL} / \mathrm{d}$ & 0.999 & $0.997-1.001$ & 0.301 \\
\hline Calcium, per increase of $1 \mathrm{mg} / \mathrm{d}$ & 0.999 & $0.996-1.002$ & 0.452 \\
\hline Phosphate, per increase of $1 \mathrm{mg} / \mathrm{d}$ & 0.999 & $0.997-1.001$ & 0.245 \\
\hline Sodium, per increase of $1 \mathrm{mg} / \mathrm{d}$ & 1.000 & $0.999-1.000$ & 0.245 \\
\hline Potassium, per increase of $1 \mathrm{mg} / \mathrm{d}$ & 1.000 & $0.999-1.000$ & 0.373 \\
\hline Iron, per increase of $1 \mathrm{mg} / \mathrm{d}$ & 0.938 & $0.841-1.048$ & 0.258 \\
\hline Eating three meals/day, per increase of 1 point & 0.821 & $0.487-1.384$ & 0.460 \\
\hline Eating various nutrients, per increase of 1 point & 0.563 & $0.296-1.072$ & 0.081 \\
\hline Number of fruits eaten/day, per increase of 1 point & 1.074 & $0.621-1.856$ & 0.798 \\
\hline Amount of milk drunk/day, per increase of 1 point & 1.122 & $0.556-2.264$ & 0.748 \\
\hline Behavior to reduce potassium, per increase of 1 point & 1.162 & $0.695-1.942$ & 0.568 \\
\hline Number of salted or processed foods, per increase of 1 point & 0.498 & $0.228-1.087$ & 0.080 \\
\hline Eating more than two protein-rich meals/day, per increase of 1 point & 0.633 & $0.360-1.111$ & 0.111 \\
\hline Eating sweet foods, per increase of 1 point & 0.891 & $0.475-1.670$ & 0.718 \\
\hline Eating out, per increase of 1 point $^{\mathrm{a}}$ & 1.837 & $1.078-3.132$ & 0.025 \\
\hline Remembering how much water to drink/day, per increase of 1 point & 0.988 & $0.547-1.784$ & 0.967 \\
\hline Fried food, per increase of 1 point $^{a}$ & 1.851 & $1.054-3.252$ & 0.032 \\
\hline Hip circumference, per increase of $1 \mathrm{~cm}$ & 1.041 & $1.011-1.072$ & 0.008 \\
\hline Waist circumference, per increase of $1 \mathrm{~cm}$ & 1.037 & $1.009-1.066$ & 0.010 \\
\hline Body mass index, per increase of $1 \mathrm{~kg} / \mathrm{m}^{2}$ & 0.868 & $0.726-1.038$ & 0.121 \\
\hline Albumin, per increase of $1 \mathrm{~g} / \mathrm{dL}$ & 0.523 & $0.074-3.713$ & 0.517 \\
\hline Eating out, per increase of 1 point $^{\mathrm{a}}$ & 1.380 & $0.698-2.727$ & 0.355 \\
\hline Fried food, per increase of 1 point $^{\mathrm{a}}$ & 2.302 & $1.022-5.184$ & 0.044 \\
\hline
\end{tabular}

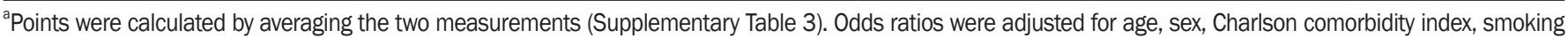
status, and medication use. 
groups (Table 3).

\section{Factors associated with nutritional status as assessed by} the SGA

Logistic regression analyses were performed to find the factors associated with poorly nourished status, as assessed by the SGA. The univariate logistic regression analyses revealed that the poorly nourished group ate fried food and ate out significantly more frequently than the well-nourished group (fried food, per 1 point increase: $\mathrm{OR}=1.851,95 \% \mathrm{CI}=1.054-3.252, P=0.032$; eating out, per 1 point increase: $\mathrm{OR}=1.837,95 \% \mathrm{CI}=$ $1.078-3.132, P=0.025)$. Moreover, higher hip and waist circumferences and lower BMI and serum albumin level were significantly associated with poorly nourished status (hip circumference per $1 \mathrm{~cm}$ increase: $\mathrm{OR}=1.015,95 \%$ $\mathrm{CI}=0.994-1.036, P=0.015$; waist circumference per $1 \mathrm{~cm}$ increase: $\mathrm{OR}=1.018,95 \% \mathrm{CI}=0.997-1.040, P=0.008$; BMI per $1 \mathrm{~kg} / \mathrm{m}^{2}$ increase: $\mathrm{OR}=0.857,95 \% \mathrm{CI}=0.746-$ $0.984, P=0.028$; serum albumin level per $1 \mathrm{~g} / \mathrm{dL}$ increase: $\mathrm{OR}=0.237,95 \% \mathrm{CI}=0.059-0.944, P=0.041)$. The variables with significant $P$ values in the univariate logistic regression analyses were included in the multivariate logistic regression analysis. In the multivariate results, only more frequent fried food intake and larger hip and waist circumferences were significantly associated with poorly nourished status (fried food, per 1 point increase: OR = 2.302, 95\% CI $=1.022-5.184, P=0.044$; Hip circumference per $1 \mathrm{~cm}$ increase: $\mathrm{OR}=1.032,95 \% \mathrm{CI}=1.002-1.063$, $P=0.036$; waist circumference per $1 \mathrm{~cm}$ increase: $\mathrm{OR}=$ $1.035,95 \% \mathrm{CI}=1.004-1.066, P=0.027$ ) (Table 4$)$.

\section{Discussion}

Malnutrition is well known to be a major contributor to the increased morbidity and younger mortality of HD patients. About $75 \%$ of HD patients suffer from proteinrelated malnutrition. Ironically, although HD is a lifesaving management technique for ESRD patients and a promising treatment for pre-dialytic chronic kidney disease patients, repetition of the HD procedure (2-3 times per week or more) removes many nutrients from dialysis patients. Moreover, HD patients are exposed to the risk of malnutrition and early mortality by restricted protein intake, increased energy consumption, inappropriate dialysis volumes, and catabolism related to dialysis [17]. Thus, proper nutritional management is important for HD patients, and the nutritional status of dialysis patients must be assessed before malnutrition can be managed [18].

During the past 20 years, a variety of tools has been used to examine the nutritional status of HD patients, and the SGA is considered to be one of the most useful [19]. In the current study, we investigated the dietary intake and patterns of HD patients, such as frequency of eating out, weekly dietary intake, and caloric intake, and compared them between the well-nourished and poorly nourished groups. We also determined the factors significantly associated with poorly nourished status, which included more frequent fried food intake and larger hip and waist circumferences.

In general, it is recommended that HD patients eat 30$35 \mathrm{kcal} / \mathrm{kg} / \mathrm{d}$ to maintain an ideal body weight. Moreover, dietitians have suggested that HD patients consume more than $1.2 \mathrm{~g} / \mathrm{kg} / \mathrm{d}$ of protein normally and more than $1.5 \mathrm{~g} / \mathrm{kg} / \mathrm{d}$ when they are malnourished. Most energy (50\%-60\%) should be obtained from carbohydrates, and the energy intake from fat should be $30 \%-35 \%[20,21]$. In terms of fluid and mineral intake, HD patients are usually encouraged to drink $750-1,500 \mathrm{~mL} / \mathrm{d}$ and to consume less than 2,000 mg/d of sodium, between 40 and 70 $\mathrm{mmol} / \mathrm{d}$ of potassium, and less than $1,000 \mathrm{mg} / \mathrm{d}$ of phosphorus.

The HD patients in this study consumed only 23.44 $\mathrm{kcal} / \mathrm{kg} / \mathrm{d}$ on average, with a mean protein intake of 0.92 $\mathrm{g} / \mathrm{kg} / \mathrm{d}$. They obtained most of their energy from carbohydrates (around $60 \%$ ) and about $23 \%$ of their energy from lipids. Moreover, these patients drank $589.06 \mathrm{~mL} / \mathrm{d}$ of water on average, and their intake of sodium, potassium, and phosphorus were $3,285.86,1,856.91$, and 760.61 $\mathrm{mg} / \mathrm{d}$, respectively, meaning that they consumed more sodium and potassium but less water and phosphorus than the KDOQI recommends. These results are similar to those of another study about nutrition in HD patients published in Korea in 2017 (energy intake: 1,411 \pm 410.5 kcal, protein intake: $55.53 \pm 21.84 \mathrm{~g} / \mathrm{d}$ in this study vs energy intake: 1,496 $\pm 401.7 \mathrm{kcal}$, protein intake: $58.28 \pm$ $23.06 \mathrm{~g} / \mathrm{d}$ in the earlier study) [22]. We found no significant differences in the intake of total energy or the major nutrient components (carbohydrates, lipids, and proteins) between the well-nourished and poorly nourished 
groups. In addition, we found no significant differences in fluid or mineral intake between the two groups. Apparently, PEW is influenced not only by energy and protein intake; other possible influences include dietary habits or behaviors, exercise, and stress. Unfortunately, we could not determine why we found no significant differences in the factors measured in our 7-day dietary research because this study was cross-sectional (one of its limitations).

We did find that the poorly nourished group ate fried food more often and had larger hip and waist circumferences than the well-nourished group. So far, only one session of nutrition education has been allowed for HD patients under the National Health Insurance coverage in Korea. The current study suggests that regular nutrition investigation and nutritional education should be required (and provided) for chronic HD patients.

As mentioned above, this study was performed via cross-sectional analysis. Thus, the causal relationship between current nutritional status and dietary intake patterns and food behaviors could not be determined, which is a limitation of this study. However, we performed 7-day dietary research and tried to determine patients' actual dietary intake and patterns. Only eight patients (7.2\%) in this study consumed more than $30 \mathrm{kcal} / \mathrm{kg} / \mathrm{d}$ and $1.0 \mathrm{~g} /$ $\mathrm{kg} / \mathrm{d}$ of protein, which suggests that most HD patients have poor energy and protein intake.

This study also had other limitations. First, we included only a small number of subjects in a restricted area. Thus, the results should be interpreted with caution, and more patients of various ethnicities should be included in future studies. Second, even though we tried to investigate a variety of foods, not all foods were included in the survey. Thus, future studies should include items that were missing from the present study. Finally, there were practical difficulties in obtaining information from all HD patients because of low compliance and a large number of non-responders and abandoners.

Although sample selection bias and measurement errors in dietary intake might have significantly influenced the results, it is nonetheless useful to evaluate dietary habits and provide proper education and consultations for HD patients. In maintenance dialysis patients, dietary management should be strictly controlled because incorrect information and lack of appetite can lead to careless dietary management. ESRD patients undergoing chronic
HD require long-term treatment, and nutritional and physical losses are inevitable during routine dialysis. Therefore, customized dietotherapy and more specific analyses of the diets of HD patients will positively influence their treatment course and quality of life.

\section{Conflicts of interest}

All authors have no conflicts of interest to declare.

\section{Funding}

This research was supported by a National Research Foundation of Korea (NRF) grant funded by the Korean government (MSIT) (2010-0027945) and by a grant of the Korea Health Technology R\&D Project through the Korea Health Industry Development Institute (KHIDI) funded by the Ministry of Health \& Welfare, Republic of Korea (grant number: HC15C1129).

\section{Authors' contributions}

Ji Eun Lee, Hyun-Jung Kim, Hyung Jung Oh, and DongRyeol Ryu were responsible for the study concept and design and data collection. Ji Eun Lee, Hyun-Jung Kim, Mi Jung Lee, Young Eun Kwon, Min-Sook Kyung, JungTak Park, Jung Pyo Lee, Su-Hyun Kim, Jung-Hyun Kim, Hyung Jung Oh, and Dong-Ryeol Ryu designed and conducted the data analysis. Ji Eun Lee, Hyung Jung Oh, and Dong-Ryeol Ryu wrote the first draft of the manuscript and had primary responsibility for the final content. Ji Eun Lee, Hyun-Jung Kim, Hyung Jung Oh, and DongRyeol Ryu revised the manuscript. All authors critically reviewed and approved the final manuscript.

\section{References}

[1] Cepoi V, Ștefan G, Mircescu G. Chronic kidney disease-a challenge for the health care systems. Manag Health 2015; 19:3.

[2] Park JI, Baek H, Jung HH. Prevalence of chronic kidney disease in Korea: the Korean National Health and Nutritional Examination Survey 2011-2013. J Korean Med Sci 2016;31: 915-923.

[3] Acchiardo SR, Moore LW, Latour PA. Malnutrition as the main factor in morbidity and mortality of hemodialysis pa- 
tients. Kidney Int Suppl 1983;16:S199-S203.

[4] Qureshi AR, Alvestrand A, Divino-Filho JC, et al. Inflammation, malnutrition, and cardiac disease as predictors of mortality in hemodialysis patients. J Am Soc Nephrol 2002; 13 Suppl 1:S28-S36.

[5] Kalantar-Zadeh K, Kopple JD, Block G, Humphreys MH. A malnutrition-inflammation score is correlated with morbidity and mortality in maintenance hemodialysis patients. Am J Kidney Dis 2001;38:1251-1263.

[6] Lazarus JM. Nutrition in hemodialysis patients. Am J Kidney Dis 1993;21:99-105.

[7] Ikizler TA, Hakim RM. Nutrition in end-stage renal disease. Kidney Int 1996;50:343-357.

[8] As'habi A, Tabibi H, Nozary-Heshmati B, Mahdavi-Mazdeh M, Hedayati M. Comparison of various scoring methods for the diagnosis of protein-energy wasting in hemodialysis patients. Int Urol Nephrol 2014;46:999-1004.

[9] Vegine PM, Fernandes AC, Torres MR, Silva MI, Avesani CM. Assessment of methods to identify protein-energy wasting in patients on hemodialysis. J Bras Nefrol 2011;33: 55-61.

[10] Gupta A, Srivastava A, Narain U, Saraswat P. Subjective global assessment of the patients of chronic kidney disease undergoing dialysis. Int J Adv Med 2017;4:481-485.

[11] Kim JH, Kim SR. Subjective global assessment of nutrition in maintenance hemodialysis patients. Korean J Nephrol 2001;20:270-276.

[12] Rattanasompattikul M, Feroze U, Molnar MZ, et al. Charlson comorbidity score is a strong predictor of mortality in hemodialysis patients. Int Urol Nephrol 2012;44:1813-1823.

[13] Desbrow B, Bauer J, Blum C, Kandasamy A, McDonald A, Montgomery K. Assessment of nutritional status in hemodialysis patients using patient-generated subjective global assessment. J Ren Nutr 2005;15:211-216.

[14] Susetyowati S, Djarwoto B, Faza F. Nutrition screening tools as predictor of malnutrition for hemodialysis patients in Dr. Sardjito Hospital in Yogyakarta, Indonesia. Saudi J Kidney Dis Transpl 2017;28:1307-1313.

[15] Detsky AS, McLaughlin JR, Baker JP, et al. What is subjective global assessment of nutritional status? JPEN J Parenter Enteral Nutr 1987;11:8-13.

[16] Kwon YE, Kee YK, Yoon CY, et al. Change of nutritional status assessed using subjective global assessment is associated with all-cause mortality in incident dialysis patients. Medicine (Baltimore) 2016;95:e2714.

[17] Sabatino A, Regolisti G, Karupaiah T, et al. Protein-energy wasting and nutritional supplementation in patients with end-stage renal disease on hemodialysis. Clin Nutr 2017;36: 663-671.

[18] Ikizler TA. Optimal nutrition in hemodialysis patients. Adv Chronic Kidney Dis 2013;20:181-189.

[19] Jones CH, Wolfenden RC, Wells LM. Is subjective global assessment a reliable measure of nutritional status in hemodialysis? J Ren Nutr 2004;14:26-30.

[20] Ash S, Campbell K, MacLaughlin H, et al. Evidence based practice guidelines for the nutritional management of chronic kidney disease. Nutr Diet 2006;63:S33-S45.

[21] Kopple JD. National kidney foundation K/DOQI clinical practice guidelines for nutrition in chronic renal failure. Am J Kidney Dis 2001;37(1 Suppl 2):S66-S70.

[22] Ryu DR, Kim JH, Kim HJ, Kyung MS, Park JT. Comparison between semi-quantitative frequency methods and 7-day dietary records methods in food and nutrition intake status for hemodialysis patients. Korean J Community Nutr 2017; 22:426-440. 